\title{
Master OnLine en Derecho Animal y Sociedad (1ª ed.)
}

Keywords: derecho animal; master; online

El Master online en "Derecho Animal y Sociedad, ha iniciado su primera edición el dia 18 de marzo de 2015. Es una gran alegría para todos y un logro muy importante que se ha conseguido gracias al apoyo y al trabajo de muchas personas.

Es el primer Máster Online del mundo en materia de Derecho Animal, con esto nos adelantamos a procurar una formación profesional a todos los que se interesen por "saber más, para trabajar mejor por los animales” y no pueden desplazarse a Barcelona para hacer el Máster presencial, que cumple este curso su $4^{\text {a }}$ edición.

El Máster cuenta, pues, con un grupo consolidado de profesionales del Derecho, de la Veterinaria, de la Bioética, de la Sociología, de la Nutrición y de la Medicina para ofrecer un programa interdisciplinar e internacional, basado en una enseñanza orientada a la práctica profesional, pero también a la investigación. Pues docencia e investigación son los dos platillos de una balanza que deben siempre mantenerse en perfecto equilibrio. De hecho, todos nuestros Alumnos del Máster online tienen que realizar un Trabajo de Fín de Máster , que está orientado y dirigido por un tutor y, en la mayoría de las ocasiones, dicho trabajo de investigación constituye el germen de la tesis doctoral, para cuya realización el SGR Grupo de Investigación ADS (=Animales, Derecho, Sociedad) de la Universitat Autònoma de Barcelona, dispone de una línea propia de investigación en el Programa de Doctorado de la Facultat de Dret de la UAB.

El Máster online cuenta con la inestimable ayuda y soporte técnico de la Editorial "Tirant lo Blanch", con una vasta experiencia en la docencia online, lo que garantiza una conexión agil y accesible para todos, tanto Profesores como Alumnos. La Universitat Autònoma de Barcelona, como es distintivo de la institución, ha estimulado la creación de este Máster online en una materia, el Derecho Animal, en la que venimos siendo pioneros desde ya hace años. En 2007 se creó oficialmente el Grupo de Investigación ADS (=Animales, Derecho, Sociedad) entre los Grupos de Investigación que posteriormente, fue reconocido como Grupo SGR por la Agencia de Qualitat (AGAUR) de la Generalitat de Catalunya.

Por último, lo que realmente le da valor al Máster es el elemento humano que lo sustenta. En primer lugar los Alumnos, por su dedicación y por su entusiasmo. El aprendizaje online, exige mucha motivación y disciplina y, desde luego, en estas primeras semanas de curso, ya apreciamos el alto nivel de formación de nuestros Alumnos de esta $1^{a}$ edición, lo que a todos los Profesores del Máster nos sirve de estímulo para mejorar. En segundo lugar, el staff del Máster, compuesto por tutores de los módulos, dos coordinadoras del Máster y la Dirección.

Para que nos conozcan nuestros Alumnos de hoy y los que en el futuro se animen a emprender esta aventura, hemos grabado un video que hemos puesto a disposición de todos en nuestro canal de YouTube (https://www.youtube.com/watch?v=pjBftDpfXzA).

Podeis contactarnos, para más información, en online@derechoanimal.info 


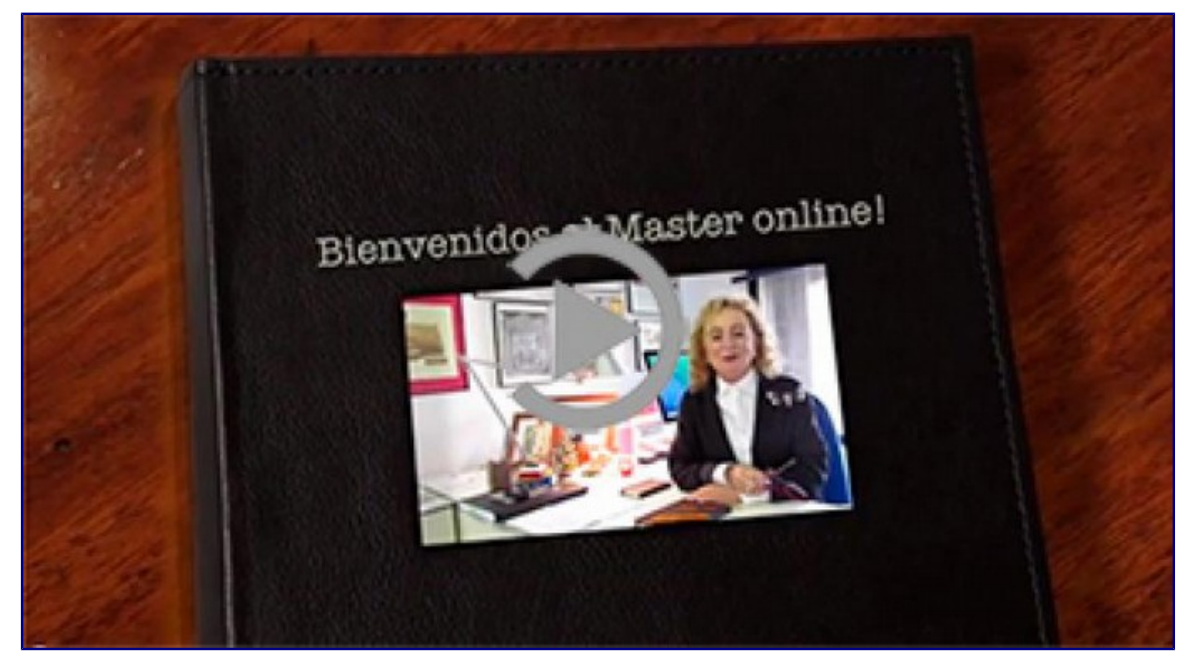

LA EDITORA

Teresa Giménez-Candela

Catedrática de Derecho Romano

Directora del Master en Derecho Animal y Sociedad Directora del SGR Grupo de Investigación ADS

Universitat Autònoma de Barcelona

Sígueme en Facebook: https://www.facebook.com/editora.da 